\title{
EDUCAÇÃO DO CAMPO NO ÂMBITO DA UNIVERSIDADE DO ESTADO DA BAHIA (UNEB): ABORDAGEM HISTÓRICA
}

\author{
Maria Jucilene Lima Ferreira (UNEB)* \\ http://orcid.org/0000-0002-0456-3842 \\ Luzeni Ferraz de Oliveira Carvalho (UNEB)** \\ http://orcid.org/0000-0002-9730-1517 \\ Maria Nalva Rodrigues de Araújo Bogo (UNEB)*** \\ http://orcid.org/0000-0002-9020-2217
}

\section{RESUMO}

Este artigo objetiva analisar o percurso histórico da Universidade do Estado da Bahia (UNEB) com projetos na Educação do Campo e a relação que se estabeleceu com a participação dos movimentos sociais populares do campo para proposição, elaboração e acompanhamento dos projetos e ações formativas realizados. A pesquisa filia-se, epistemologicamente, ao Materialismo HistóricoDialético, apoiando-se na pesquisa/participante/ação e se utiliza da revisão de literatura e pesquisa documental no processo de investigação. Os resultados apontam possibilidades e situações limites de diálogo e trabalho coletivo com os Movimentos Sociais e Sindicais Populares do Campo para a realização de projetos com a Educação do Campo no percurso histórico de 26 anos. Concluise que a universidade tem buscado implementar novas frentes de trabalho, sob a escuta das demandas dos movimentos e princípios do trabalho coletivo, portanto, sinalizam-se possibilidades de se reafirmar o seu compromisso social com os povos do campo.

Palavras-chave: Educação do Campo. UNEB. Formação.

\section{ABSTRACT}

\section{RURAL EDUCATION AS SCOPE OF THE BAHIA STATE UNIVERSITY: HISTORICAL APPROACH}

This article aims to analyze Bahia State University (UNEB) historical path with projects in Rural Education and the relationship that was established with the participation of popular social movements of the countryside for propose, elaborate and monitor projects and training actions carried out. The research

\footnotetext{
* Doutora em Educação pela Universidade de Brasília (UnB). Professora Adjunta da Universidade do Estado da Bahia (UNEB). Universidade do estado da Bahia. Salvador Bahia Brasil. E-mail: mjferreira@uneb.br

** Doutora em Educação pela Universidade de Brasília (UnB). Professora Assistente da Universidade do Estado da Bahia. Universidade do Estado da Bahia. Salvador Bahia Brasil. E-mail: lfcarvalho@uneb.br

*** Doutora em Educação pela Universidade Federal da Bahia (UFBA). Professora Titular da Universidade do Estado da Bahia (UNEB). Universidade do Estado da Bahia. Salvador Bahia Brasil E-mail: mnbogo@uneb.br
} 
is epistemologically affiliated with Historical Dialectical Materialism and uses literature review and documentary research in the investigation process. The results point out limit situations, dialogue possibilities and collective work with the Social and Popular Union Movements of the Countryside to realize projects with Rural Education in the historical path of 26 years. It is concluded that the university has sought to implement new work fronts, listening to the movements demands and collective work principles, therefore, it indicates possibilities to reaffirm its social commitment to the countryside people.

Keywords: Rural Education. UNEB. Formation.

\section{RESUMEN \\ EDUCACIÓN DE CAMPO NO ÂMBITO DE LA UNIVERSIDAD DEL ESTADO DE BAHIA: ABORDAGEM HISTÓRICA}

Este artículo apunta analizar la trayectoria histórica de la Universidad del Estado de Bahía (UNEB) con proyectos en Educación Rural y la relación que se estableció con la participación de los movimientos sociales populares del campo para proponer, elaborar y monitorear los proyectos y acciones formativas realizadas. La investigación está epistemológicamente afiliada al materialismo histórico dialéctico y utiliza la revisión de la literatura y la investigación documental en el proceso de investigación. Los resultados señalan situaciones limite, posibilidades de diálogo y trabajo colectivo con los Movimientos Populares Sociales y Sindicales del Campo para la realización de proyectos con Educación Rural en la trayectoria histórica de 26 años. Se concluye que la universidad ha buscado implementar nuevos frentes de trabajo, escuchando las demandas de los movimientos y principios del trabajo colectivo, por lo que señala posibilidades para reafirmar su compromiso social con la gente del campo.

Palabras-clave: Educación rural. UNEB. Formación.

\section{Introdução}

A Educação do Campo é um projeto político -pedagógico da classe trabalhadora do campo que se posiciona na defesa dos interesses dos que foram historicamente excluídos do acesso aos bens materiais e imateriais/simbólicos, e entre estes o acesso à terra e à educação.

Por isso, falar em Educação do Campo é discorrer acerca da reação dos trabalhadores organizados frente a uma história de exclusões. Desde a chegada dos colonizadores, em 1500 , até os dias atuais, 2020, observamos que o campo brasileiro tem se transformado de forma crescente e veloz. No entanto, essas transformações ocorridas no campo estão bem longe de serem favoráveis aos trabalhadores.
Ao contrário, as mudanças ocorridas vão deixando para trás um rastro de concentração histórica de terras, marcas de trabalho escravo, violência, exclusão, marginalização, desemprego, subemprego, endividamento dos pequenos produtores, êxodo rural, analfabetismo, falta de acesso à educação e a escolas, entre outros.

Conforme o Censo Agropecuário de 2006, o nível de desigualdade fundiária no território brasileiro, entre os anos de 1985 e 2006, permaneceu praticamente sem alteração; o índice de Gini $^{1}$ de 0,856 registrado para 2006 ficou no mesmo patamar dos que foram registrados nos anos 1995, 1985 e 1975, que

1 Índice que é usado para medir a concentração de um bem. 
foram, respectivamente, 0,857, 0,858 e 0,855 (INSTITUTO BRASILEIRO DE GEOGRAFIA E ESTATÍSTICA, 2009).

Os dados do citado Censo indicam que, dos estabelecimentos existentes no Brasil, 4,36 milhões são de atividades ligadas à pequena agricultura. Estes ocupam uma área de 80,25 milhões de hectares, equivalente a $24,3 \%$ da área ocupada. De outro lado, os estabelecimentos das grandes propriedades, apesar de representarem somente $15,6 \%$ dos estabelecimentos, ocupam 75,7\% da área (INSTITUTO BRASILEIRO DE GEOGRAFIA E ESTATÍSTICA, 2009).

Quanto à violência no campo, o Relatório da Comissão Pastoral da Terra (2020) mostra que, em 2019, ocorreram mais de 1.800 conflitos no campo por terra, água e trabalho. É o maior número dos últimos 15 anos, tendo como consequência a ocorrência de 32 assassinatos em 2019.

De acordo com dados da Pesquisa Nacional por Amostra de Domicílios (PNAD), a Bahia é o Estado com a maior proporção de população rural (3.914.430 habitantes) em relação à urbana (10.102.476 habitantes), e cerca de um terço da população rural do Estado vive em extrema pobreza (1.287.177 habitantes), ou seja, 53,45\% dos considerados extremamente pobres do estado vivem no campo (INSTITUTO BRASILEIRO DE GEOGRAFIA E ESTATÍSTICA, 2010). Dados do Instituto de Pesquisas Econômica Aplicada (IPEA) mostram que $17,6 \%$ da população rural do estado da Bahia são extremamente pobres, em contraposição a 6,9\% da população urbana, e 34\% dos extremamente pobres do estado são agricultoras familiares (CASTRO, 2011).

Quanto ao acesso à terra, no estado da Bahia, por meio de lutas empreendidas pelos movimentos e organizações populares, dados do Grupo de Pesquisa Geografar, da Universidade Federal da Bahia (UFBA) mostram que, em 2010 , eram 330 acampamentos, 480 projetos de reforma agrária, 111 assentamentos do Programa Cédula da Terra, 158 assentamentos do Crédito Fundiário, 454 comunidades de fundo e fecho de pasto, 769 comunidades quilombolas (dessas, 438 eram certificadas pela Fundação Cultural Palmares), 237 colônias e associações de pescadores e 28 povos indígenas. Esses dados indicam a gravidade das disputas pelos territórios existentes no estado, pois muitos desses grupos sociais vivem em áreas de conflito por terras com fazendeiros e são atingidos por grandes obras do capital, legitimadas pelo Estado (GEOGRAFAR, 2013).

No que se refere à educação, o meio rural concentra a maior taxa de analfabetismo de pessoas com mais de 15 anos (25,8\%), a maior taxa de distorção idade-série - até a quarta série são 41,4\%, de quinta a oitava séries são $56 \%$ e no ensino médio são $59,1 \%$. No que se refere ao estado da Bahia, dados do Instituto Nacional de Estudos e Pesquisa Anísio Teixeira (INEP) revelam o estado possui 29,8\% dessa população rural adulta com mais de 15 anos em situação de analfabetismo. Os dados citados aqui mostram a necessidade de uma universidade comprometida, aberta às reivindicações das populações do seu entorno (INSTITUTO NACIONAL DE ESTUDOS E PESQUISAS EDUCACIONAIS ANÍSIO TEIXEIRA, 2009).

A Universidade do Estado da Bahia (UNEB) é uma universidade que, por sua configuração multicampi, se encontra presente em distintos Territórios de Identidade da Bahia (BAHIA, 2020). São 24 campi e 29 Departamentos, em 25 municípios baianos. Trata-se de uma instituição pioneira na formação de professores pela articulação entre ensino, pesquisa e extensão. Acreditamos que, por essa razão, o trabalho formativo com a Educação do Campo tenha se iniciado no âmbito das ações da extensão universitária. Segundo Bogo (2017, p. 126), professora, pesquisadora e extensionista na área de Educação de Jovens e Adultos (EJA) e Educação do Campo na UNEB, "é preciso reconhecer a existência de ações de extensão e pesquisa em educação para o povo do meio rural, realizadas na UNEB, antes do Movimento Por Uma Educação do Campo, no final dos anos 1990". 
Ainda segundo Bogo (2017), essas ações foram desenvolvidas no Departamento de Ciências Humanas (DCH III), no município de Juazeiro, e no Departamento de Educação (DEDC-X), em Teixeira de Freitas. Tais ações - que também podem ter ocorrido em outros Departamentos - possibilitaram a aproximação da UNEB com as populações campesinas, seus dilemas e problemas, e, possivelmente, construíram as bases para o envolvimento da Universidade com a Educação do Campo, a partir do movimento desencadeado.

A partir do exposto, problematizamos: Que ensinamentos são possíveis apreender em termos de compreensão das relações entre a função social da universidade e as demandas dos movimentos sociais e sindicais populares do campo? Busca-se, assim, com este artigo, analisar o percurso histórico da Universidade do Estado da Bahia no que se refere aos projetos realizados no âmbito da Educação do Campo e à relação que se estabeleceu com a participação dos movimentos sociais populares do campo para proposição, elaboração e acompanhamento dos projetos e ações formativas realizadas.

Quanto aos caminhos teórico-metodológicos, a pesquisa filia-se epistemologicamente ao Materialismo Histórico-Dialético, apoiando-se na pesquisa/participante/ação. Trata-se de um trabalho em que, ao mesmo tempo que se percorre a investigação, se está diretamente envolvido com o objeto de estudo, na relação indissociável com esse objeto, utilizando-se da revisão de literatura e pesquisa documental. Para tanto, catalogou-se projetos e relatórios de cursos de licenciaturas, bacharelados e pósgraduação; projetos de cursos de extensão, relatório de eventos de extensão, Diário Oficial do Estado da Bahia e do município de Conceição do Coité, Resoluções do Conselho Universitário da UNEB e arquivos documentais da Secretaria Administrativa do Centro Acadêmico de Educação do Campo e Desenvolvimento Territorial (CAECDT).

\section{0 compromisso social da}

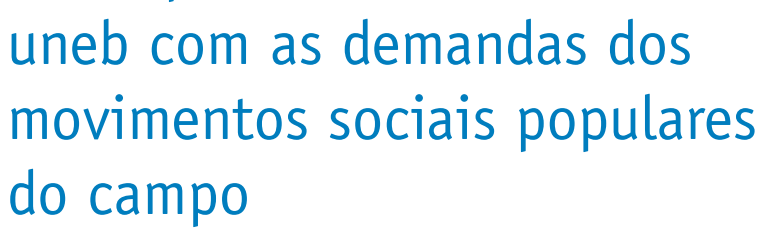

A UNEB, ao longo de seus 37 anos de existência, tem atuado buscando comprometer-se, cada vez mais, com a sua missão de produzir conhecimento, divulgá-lo, disponibilizá-lo e torná-lo acessível a um universo populacional cada vez maior. Nessa perspectiva, os projetos pedagógicos dos cursos de graduação existentes na UNEB têm se ocupado da organização didático-pedagógica, possibilitando contemplar as especificidades dos Territórios de Identidade de abrangência de cada um dos 24 Campi, na perspectiva de articular ensino, pesquisa e extensão universitária.

Trata-se de um projeto de gestão universitária, garantida no Plano de Desenvolvimento Institucional (PDI) 2017-2022, da UNEB (UNIVERSIDADE DO ESTADO DA BAHIA, 2017b), o qual se define por construir uma política permanente de interiorização de cursos de graduação e de pós-graduação lato e stricto sensu. Assim, pari passu, a Universidade avança estabelecendo compromissos sociais com os municípios baianos e comunidades campesinas. Nesse sentido, sua configuração multicampi favorece a possibilidade de as camadas populares, sobretudo aquelas organizadas pela noção e princípio de sujeito coletivo de direito, acessarem o ensino superior, isso porque a sua presença no território, de algum modo, evidencia concretamente a contradição de privilégio de acesso e permanência para uns em detrimento de outros.

A implantação dos cursos de graduação, projetos de pesquisa e extensão obedecem às necessidades e demandas por formação pessoal e profissional do cidadão e, consequentemente, com o desenvolvimento do contexto onde os Departamentos (unidades acadêmicas) estão inseridos, e, por conseguinte, possibilita, ainda, o estabelecimento de relações diretas com as 
demandas formativas dos sujeitos coletivos de direito, principalmente nos idos finais dos anos de 1990, quando, a partir da conquista das/os camponesas/es, organizadas/os, com o lançamento do Programa Nacional de Educação na Reforma Agrária (Pronera).

O objetivo do Pronera é promover a educação nos assentamentos de Reforma Agrária, estimulando, propondo, criando, desenvolvendo e coordenando projetos educacionais utilizando metodologias específicas para o campo. Desde essa intencionalidade, o Programa propicia condições materiais para o processo de escolarização no âmbito do Ensino Fundamental, do Ensino médio e superior, mas, sobretudo, imprime nesse processo concepções e princípios formativos orgânicos à classe trabalhadora camponesa.

Assim, a exemplo da política que se desencadeia com o Pronera, o artigo $2^{\circ}$ do Decreto no 7.352, de novembro de 2010 (BRASIL, 2010), reafirma os princípios da Educação do Campo, referindo-se no inciso I ao "respeito à diversidade do campo em seus aspectos sociais, culturais, ambientais, políticos, econômicos, de gênero, geracional e de raça e etnia". Isso significa dizer que os princípios da Educação do Campo não tratam de qualquer formação, mas daquela que se coloca crítica e de perspectiva emancipadora, sobretudo porque busca romper, superar, transformar a lógica dos processos educativos sob os ditos do capital e a lógica dos meios de produção da vida no campo. Acrescente-se a isso o lugar de relevância político-formativa que a luta social assume nas proposições do Projeto de Educação do Campo, tanto no sentido do seu próprio fortalecimento, quanto da potencialidade formativa para os sujeitos, pois:

Dizer que a luta social pode educar as pessoas significa afirmar que o ser humano se forma não apenas através de processos de conformação social, mas ao contrário, que há traços de sua humanidade construídos nas atitudes de inconformismo e contestação social, e nas iniciativas concretas de lutar pela transformação do 'atual estado de coisas'. (CALDART, 2012, p. 39-40).
Daí é forçoso afirmar que a peculiaridade dos princípios da Educação do Campo explícitos, também no Pronera, indaga não só os pressupostos teórico-metodológicos da educação básica e superior, mas inclui, na discussão particular, a própria instituição universitária. Ou seja, "os movimentos interrogam as universidades ao exigirem destas, não só o acesso à escolarização formal, mas a sua verdadeira democratização, trazendo para a escola a heterogeneidade social, econômica e cultural existentes no campo brasileiro atualmente" (MOLINA; ANTUNES-ROCHA, 2014, p. 234).

No caso da UNEB, destacam-se ao menos duas linhas de trabalho de profícuo aprendizado, a primeira relacionada à gestão de processos educativos nos cursos de Licenciaturas e Bacharelado (Pedagogia, Letras, Engenharia Agronômica, Direito e Educação do Campo - Procampo). quando essa gestão, desde a elaboração dos projetos de cursos, se deu não a partir inteiramente da produção intelectual das/os pesquisadoras/es da universidade, mas com o diálogo e atendimento de interesses específicos do setor de educação dos movimentos que demandaram os cursos.

Quanto à segunda linha, está relacionada à Organização do Trabalho Pedagógico, na medida em que os movimentos reivindicam conhecimento curricular específico para a formação de seus quadros de lideranças e, também, coordenam a realização do curso em parceria com a universidade, participando efetivamente da organização e orientação do trabalho pedagógico planejado.

No entanto, salienta-se que esse processo de produção colaborativa entre universidade e movimentos sociais não se dá sem tensões e conflitos entre as partes, sobretudo porque de um lado encontra-se a universidade como instituição secular, produtora de conhecimento, regida por protocolos que, contrariamente ao que sugere a semântica do termo que a intitula (universidade - universalidade, totalidade), em larga medida se atém à negação do conhecimento popular e à produção de conhecimento 
a serviço da vida das pessoas; e de outro lado, por parte dos movimentos sociais, há a crítica aleatória e contundente, a preocupação com o comportamento e ações dos militantes, com vistas ao controle dos princípios do movimento sobrepondo-se à ampliação de processos de consciência acerca da estrutura organizativa do próprio movimento. Ou seja, expressões de contradições próprias do contexto social em que ambas as organizações estão inseridas.

A partir do ano de 1999, considerando a sua responsabilidade com a ciência e a comunidade da qual faz parte, a UNEB, em parceria com o Ministério do Desenvolvimento Agrário (MDA), por meio do Instituto Nacional de Colonização e Reforma Agrária (INCRA), o Programa Nacional de Educação na Reforma Agrária (PRONERA) e os Movimentos Sociais e Sindicais Populares que atuam no Campo, ${ }^{2}$ implantou projetos de formação escolar na modalidade de Educação de Jovens e Adultos (Projeto Pé na Estrada) e Ensino Médio Integrado à Educação Profissional como os Cursos de Magistério e Técnico em Agropecuária Sustentável, dentre outros que podem ser verificados no Quadro 1 a seguir.

Quadro 1 - Projetos/Cursos UNEB/Educação Básica

\begin{tabular}{|c|c|c|c|c|c|}
\hline PROJETO / CURSO & PROGRAMA & DEPARTAMENTOS & $\begin{array}{c}\text { ANO } \\
\text { INICIAL }\end{array}$ & $\begin{array}{l}\text { PÚBLICO } \\
\text { INICIAL }\end{array}$ & $\begin{array}{l}\text { PÚBLICO } \\
\text { FINAL }\end{array}$ \\
\hline $\begin{array}{l}\text { Projeto de Educação e } \\
\text { Capacitação de Jovens e } \\
\text { Adultos na Reforma Agrária } \\
\text { / Alfabetização }\end{array}$ & PRONERA & $\begin{array}{l}\text { Teixeira de Freitas, } \\
\text { Bom Jesus da Lapa, } \\
\text { Barreiras e Irecê }\end{array}$ & 1999 & 4.800 & 4.604 \\
\hline $\begin{array}{l}\text { Projeto de Educação e } \\
\text { Capacitação de Jovens e } \\
\text { Adultos na Reforma Agrária } \\
\text { / Ensino Fundamental de 5⿳亠丷a } \\
\text { a } 8 \text { a séries }\end{array}$ & PRONERA & $\begin{array}{l}\text { Teixeira de Freitas, } \\
\text { Bom Jesus da Lapa, } \\
\text { Barreiras e Irecê }\end{array}$ & 1999 & 240 & 111 \\
\hline $\begin{array}{l}\text { Projeto Letras em } \\
\text { Movimento/ Alfabetização }\end{array}$ & PRONERA & $\begin{array}{l}\text { Teixeira de Freitas, } \\
\text { Bom Jesus da Lapa, } \\
\text { Barreiras, Irecê, } \\
\text { Alagoinhas, Jacobina, } \\
\text { Eunápolis, Valença. }\end{array}$ & 2001 & 4.900 & 2.667 \\
\hline $\begin{array}{l}\text { Projeto Letras em } \\
\text { Movimento / Ensino } \\
\text { Fundamental de } 5^{a} \text { a } 8 \stackrel{\text { a }}{ } \\
\text { séries }\end{array}$ & PRONERA & $\begin{array}{l}\text { Teixeira de Freitas, } \\
\text { Bom Jesus da Lapa, } \\
\text { Barreiras, Irecê, } \\
\text { Alagoinhas, Jacobina, } \\
\text { Eunápolis, Valença }\end{array}$ & 2001 & 245 & 219 \\
\hline $\begin{array}{l}\text { Ensino Médio na } \\
\text { Modalidade Normal / } \\
\text { Magistério }\end{array}$ & PRONERA & $\begin{array}{l}\text { Teixeira de Freitas e } \\
\text { Bom Jesus da Lapa }\end{array}$ & 2002 & 80 & 80 \\
\hline
\end{tabular}

Fonte: Elaborado pelas autoras deste artigo com base em Universidade do Estado da Bahia (2020).

Em que pese o grau de precarização das condições materiais para a realização do trabalho pedagógico em espaço físico de pouca ventilação e luminosidade, com escassez de material didático, e a divisão do tempo do estudante para conciliar trabalho e estudo, cabe ressaltar que, em essência, os programas de oferta desses cursos buscaram atender à prer-
2 Os Movimentos Sociais e Sindicais Populares do campo que estiveram à frente das demandas de cursos junto à UNEB foram: Movimento dos Trabalhadores Rurais Sem Terra (MST), Movimento de Trabalhadores Rurais Assentados e Acampados (CETA), Movimento de Luta pela Terra (MLT), Federação dos Trabalhadores Agricultores e Agricultoras Familiares (FETAG), Fundação de Apoio à Agricultura Familiar do Semiárido da Bahia (FATRES), Fundação do Desenvolvimento Integrado do São Francisco (FUNDIFRAN), Polo de Unidade Camponesa (PUC), Pastoral da Terra, Fundo e Feixe de Pasto. 
rogativa das demandas do projeto originário da Educação do Campo, qual seja:

Projeto de educação que não se limita apenas à escolarização das crianças, jovens e adultos que vivem no campo, mas também envolve a cultura, a produção de valores de cunho socialista, a formação para o trabalho e o profundo diálogo com a realidade social do campo. (FERREIRA, 2015, p. 91).

Nesse sentido, evidencia-se que os fundamentos das proposições curriculares para o atendimento às demandas formativas das/os trabalhadoras/es do campo não estão dissociados das dimensões políticas e socioculturais, ancoram-se na perspectiva crítica e emancipadora, com vistas a contribuições formativas para a elevação da consciência da realidade social em que se produz a vida no campo. Ora, do lugar da Universidade, se se pretende corresponder com os chamados sociais de um coletivo (movimentos sociais e sindicais) os quais se colocam a serviço da luta social pela melhoria das condições de produção da vida; se se depara com o imperativo de um coletivo que apresenta protagonismo, organicidade e intencionalidade com as questões da educação e dos processos formativos que lhes são próprios, nada mais oportuno e justo que se atue em consonância com tais demandas, sob princípios éticos, inerentes ao trabalho formativo dessa natureza.

Segundo o que consta no Regimento Geral da Universidade do Estado da Bahia (2012), assim como no Plano de Desenvolvimento Institucional (2017-2022) (UNIVERSIDADE DO ESTADO DA BAHIA, 2017b), o objetivo maior da instituição é
Promover a formação integral do cidadão e o desenvolvimento das potencialidades econômicas, tecnológicas, sociais, culturais, artísticas e literárias da comunidade baiana, sob a égide dos princípios da ética, da democracia, das ações afirmativas, da justiça social, pluralidade étnicocultural e demais princípios do Direito Público. (UNIVERSIDADE DO ESTADO DA BAHIA, 2012, p. 5).

Desde essa compreensão de trabalho socioformativo apresentado e discutido até aqui, a UNEB buscou, cada vez mais, consolidar seu compromisso social, também, com o atendimento das demandas dos Movimentos Sociais e Sindicais Populares do Campo, no processo de interiorização do ensino superior nos municípios baianos. Trata-se de um compromisso que, em larga medida, contribui com a ampliação do patrimônio cultural da população baiana, tanto por parte da UNEB, como por parte das demais Instituições de Ensino Superior baianas. Assim, é forçoso afirmar que "o acesso à educação superior pública na Bahia foi mantido e ampliado pelas universidades estaduais. Foram elas - são elas - que têm sustentado expressiva oferta pública da educação superior no Estado" (FIALHO, 2012, p. 26).

Por conseguinte, além dos cursos supracitados, no início dos anos 2000 são ofertados aos sujeitos do campo, no âmbito da UNEB, cursos de ensino superior a partir do Pronera e seguindo as mesmas prerrogativas citadas anteriormente, quais sejam, as demandas de cursos oriundas dos Movimentos Sociais e Sindicais Populares do Campo para assentados e quilombolas envolvendo sujeitos integrados a movimentos populares. Assim, foram ofertados os cursos organizados no Quadro 2 a seguir.

Quadro 2 - Cursos de Graduação Licenciatura e Bacharelados UNEB/PRONERA

\begin{tabular}{|c|c|l|c|c|c|}
\hline PROJETO / CURSO & PROGRAMA & \multicolumn{1}{|c|}{$\begin{array}{c}\text { ASSENTAMENTO/ } \\
\text { DEPARTAMENTOS }\end{array}$} & $\begin{array}{c}\text { ANO } \\
\text { INICIAL }\end{array}$ & $\begin{array}{c}\text { PÚBLICO } \\
\text { INICIAL }\end{array}$ & $\begin{array}{c}\text { PÚBLICO } \\
\text { FINAL }\end{array}$ \\
\hline Pedagogia da Terra & PRONERA & $\begin{array}{l}\text { DEDC X - Teixeira de } \\
\text { Freitas/ Assentamento 1o } \\
\text { de Abril, em Prado) e } \\
\text { DCHT XVII - Bom Jesus da } \\
\text { Lapa }\end{array}$ & 2003 & 120 & 92 \\
\hline
\end{tabular}


Quadro 2 - Continuação

\begin{tabular}{|l|c|l|c|c|c|}
\hline \multicolumn{1}{|c|}{ PROJETO / CURSO } & PROGRAMA & \multicolumn{1}{|c|}{$\begin{array}{c}\text { ASSENTAMENTO/ } \\
\text { DEPARTAMENTOS }\end{array}$} & $\begin{array}{c}\text { ANO } \\
\text { INICIAL }\end{array}$ & $\begin{array}{c}\text { PÚBLICO } \\
\text { INICIAL }\end{array}$ & $\begin{array}{c}\text { PÚBLICO } \\
\text { FINAL }\end{array}$ \\
\hline $\begin{array}{l}\text { No Cio da Terra, o } \\
\text { Germinar das Letras } \\
\text { em Movimento / } \\
\text { Letras da Terra }\end{array}$ & PRONERA & $\begin{array}{l}\text { DEDC X - Teixeira de Freitas } \\
\text { (Assentamento 10 de Abril } \\
\text { - Prado) e DEDC XIV - } \\
\text { Conceição do Coité }\end{array}$ & 2005 & 120 & 96 \\
\hline $\begin{array}{l}\text { Bacharelado } \\
\text { em Engenharia } \\
\text { Agronômica }\end{array}$ & PRONERA & $\begin{array}{l}\text { DEDC IX - Barreiras e } \\
\text { Assentamento Terra Vista- } \\
\text { Arataca }\end{array}$ & 2006 & 100 & 85 \\
\hline $\begin{array}{l}\text { Bacharelado em } \\
\text { Direito }\end{array}$ & PRONERA & DEDC I - Salvador & 2012 & 50 & 41 \\
\hline
\end{tabular}

Fonte: Elaborado pelas autoras deste artigo com base em Universidade do Estado da Bahia (2020).

A partir dos objetivos formativos delimitados em cada projeto de curso, evidenciam-se os princípios e perspectivas do perfil profissional para o processo de formação da/o estudante, bem como se verificam nesses projetos características próprias para a atuação militante desse profissional em formação. Para citar alguns exemplos, destacaram-se os objetivos de cada projeto de curso, considerando que esses explicitam, de algum modo, a linha de trabalho teórico-metodológica perseguida nos processos formativos em voga. Por exemplo, no Curso de Pedagogia da Terra, ofertado pelo Departamento de Educação, Campus X e pelo Departamento de Ciências Humanas e Tecnologias, Campus XVII, a turma vinculada ao DEDC X ocorreu no Assentamento $1^{\mathrm{o}}$ de Abril.

Na medida em que o debate sobre os ataques ambientais ecoa em vários cantos do mundo e a luta dos Movimentos Sociais e Sindicais Populares do Campo pela garantia do direito à educação é cada vez mais urgente, o debate acerca da formação de educadoras e educadores do campo - além de concepções e práticas acerca da Educação Infantil e dos anos iniciais do Ensino Fundamental - na Educação Básica se fez e se faz elementar. Dentre outros elementos previstos nos objetivos específicos do Projeto Político-Pedagógico do Curso de Pedagogia da Terra, destaca-se "exercer a docência nas séries iniciais do ensino fundamental e em classes de jovens e adultos pautando-a em princípios como a dialogicidade, a construção coletiva e a leitura ética/estética e política da realidade do campo" (UNIVERSIDADE DO ESTADO DA BAHIA, 2003, p. 16).

Vê-se, portanto, uma perspectiva de docência que busca estabelecer relação horizontal com os sujeitos envolvidos com os processos de ensino e aprendizagem, respaldada em diálogo fecundo sobre si, o outro e o mundo, bem como uma docência articulada à dimensão crítica e política sobre a realidade de produção da vida no campo. Trata-se, sobretudo, da construção da docência militante, ou seja, aquela docência perseguida por "valores de um militante ativo social” (PISTRAK, 2000, p. 26). A despeito do acúmulo de produção de conhecimento acerca dessa prerrogativa militante, a docência é amplamente debatida, no sentido da pertinência e organicidade necessárias ao fortalecimento da luta social dos povos que vivem nos territórios rurais.

Quanto ao Curso de Letras, ofertado pelos Departamentos de Educação de Teixeira de Freitas (Campus X) e Conceição do Coité (Campus XIV), sendo que o do Campus X ocorreu no Assentamento $1^{\text {o }}$ de Abril, o Relatório Parcial do Desenvolvimento do Curso (UNIVERSIDADE DO ESTADO DA BAHIA, 2010, p. 3-4) registra a "realização de "projetos de ensino, pesquisa e extensão, produção e divulgação do conhecimento acerca da leitura, escrita e literatura no ensino de Língua Portuguesa e na Educação do Campo". 
Na medida em que os Movimentos Sociais Populares do Campo compreendem a educação e o conhecimento escolar como força motriz na luta pela Reforma Agrária Popular, fazem suas reivindicações por formação inicial e continuada, em nível superior, para educadoras e educadores do campo, sob a perspectiva crítica e política tanto para os processos de formação quanto para os aprendizados e exercício da docência. Por isso, algumas atividades que constam no referido relatório apontam como objetivo principal do trabalho formativo "estudar, pesquisar, produzir e sistematizar conhecimentos acerca da área de Língua Portuguesa, Literatura, Cultura, Sociedade e Educação, visando a formação crítica e política de educadores/as do campo" (UNIVERSIDADE DO ESTADO DA BAHIA, 2010, p. 4).

O Curso de Direito (2012 a 2018), ofertado pelo Departamento de Educação - Campus I, em Salvador, se constituiu como mais uma relação expressiva da universidade com os Movimentos Sociais e Sindicais Populares do Campo, sobretudo por dedicar-se a contribuir com a formação de bacharéis/bacharelas em Direito sob a perspectiva popular, da luta por justiça e igualdade social.

O Curso de Direito da UNEB tem por finalidade mais ampla: formar bacharéis em Direito com forte concentração de estudos interdisciplinares nas áreas das ciências humanas e sociais direcionados ao exercício das diversas atividades da área jurídica, para o compromisso com o ideal de justiça e com o processo de transformação social (UNIVERSIDADE DO ESTADO DA BAHIA, 2012a, p. 17).

Desde essa prerrogativa formativa, cabe destacar que o supracitado curso se origina de acirrada disputa, de âmbito federal, e enfretamento de tensões colocadas como impeditivos para a oferta dele para a classe trabalhadora camponesa. Exemplos disso foram o Curso de Direito, na Universidade Federal de Goiás, de Agronomia, no Pará, e de Medicina Veterinária, no Rio Grande do Sul. A esse respeito, segundo Molina (2010, p. 142),
[...] questiona-se, na Audiência [Pública do Parlamento], a absurda limitação a determinados campos do conhecimento científico para estes trabalhadores, que conforme argumentos de uma das ações impetradas contra o [Pronera], os sujeitos do campo não precisam estudar direito [...]

Vale ressaltar que, desde a elaboração dos Projetos Político-Pedagógicos de cada curso, bem como as práticas formativas concretas, as quais foram planejadas nesses projetos, discutidas em relatórios parciais dos cursos e autoavaliadas no percurso da formação, se constata, por conseguinte, processos formativos que visam contribuir, sobremaneira, com a ampliação da consciência de trabalhadoras e trabalhadores rurais e da sociedade de modo mais abrangente. E, ainda, é forçoso afirmar que,

O conjunto de ações, a execução de cursos em várias áreas de conhecimento, com a oferta de diferentes níveis de escolarização, da alfabetização à pós-graduação, tem provocado mudanças na representação social sobre a percepção dos trabalhadores rurais como sujeitos de direito. (MOLINA, 2010, p. 142).

Nesse sentido, a relação entre universidade, Educação do Campo e Movimento Sociais e Sindicais Populares do Campo se caracteriza por um trabalho coletivo, ${ }^{3}$ reúne mais forças em prol da transformação da sociedade, de modo que nela se fortaleça a Educação como Direito, a Soberania Alimentar e Popular e a produção da vida no campo de modo digno e justo. Daí que o trabalho coletivo se faz elementar, pois dele emana elementos circunstanciais para as bandeiras e o perfil da luta, tais como definição de intencionalidades comuns aos distintos

3 Por trabalho coletivo se entende aquele que não se atém apenas a uma divisão de tarefas ou à presença do outro, mas a um modo particular de participação que expressa envolvimento efetivo das partes na construção e desenvolvimento da tarefa. Em vez de ser uma divisão de tarefas para um grupo de pessoas resolver um problema ou mesmo atingir um determinado fim, são atividades que envolvem pessoas cientes da finalidade do próprio trabalho e do seu conjunto, da importância desse trabalho e de suas etapas. Essas pessoas se dispõem a avaliar, continuadamente, o andamento do trabalho individual e coletivo, bem como seus respectivos resultados (FERREIRA; MOLINA, 2016). 
coletivos da universidade e dos movimentos, organicidade formativa para ambas as partes e produção de conhecimento em favor da elevação da cultura e da consciência dos povos campesinos.

Quanto ao Curso de Bacharelado em Engenharia Agronômica, foram ofertadas duas turmas, cada uma com 50 vagas, uma no Departamento de Ciências Humanas - Campus IX, no município de Barreiras, e outra no Assentamento Terra Vista, no município de Arataca. Esse Curso objetivou:

Formar Engenheiros Agrônomos entre trabalhadores e trabalhadoras dos Movimentos Sociais do campo para atuarem em áreas de assentamentos de Reforma Agrária no Estado da Bahia, mediante a oferta do Curso de Bacharelado em Engenharia Agronômica, pela Universidade do Estado da Bahia - UNEB/ Departamento de Educação-DEDC, Campus IX, numa perspectiva da Educação do Campo com ênfase em Agroecologia e Sócio - Economia Solidária, os quais sejam capazes de aproveitarem as potencialidades regionais e solucionarem os problemas da Agricultura Familiar Camponesa nas áreas de assentamentos. (UNIVERSIDADE DO ESTADO DA BAHIA, 2006, p. 67).

De modo particular, por si só, a oferta desse curso caracteriza mais uma peculiaridade do compromisso social da UNEB com a Educação do Campo e o trabalho coletivo de formação junto aos Movimentos Sociais e Sindicais Populares do Campo, pois, sobretudo, na oferta de um curso superior que se faz no interior do território de um assentamento de Reforma Agrária pode-se denominá-la de uma "ação revolucionária", ao menos por três argumentos, a saber: 1) Primeiramente, ao ofertar de um curso em que a área de conhecimento é privilegiada socialmente, em detrimento da área de Humanas, por exemplo, por ser um curso demandado pelos sujeitos coletivos de direitos, a UNEB oportuniza o acesso e a permanência desses sujeitos no referido curso; 2) Um curso de ensino superior realizado dentro das dependências físicas do Assentamento atribui, não só aos estudantes, mas a toda comunidade assentada, o sentimento e a condição material de pertencimento, ou seja, um curso que lhe é próprio; e 3) Para a implementação de uma oferta de curso, tal como descrita, necessariamente a universidade se desvencilha do lugar hierárquico, como instituição produtora do conhecimento válido, para dar lugar ao diálogo e à produção científica com o conhecimento dos povos campesinos na construção da ciência a serviço da vida das pessoas e do lugar, sem abdicar do rigor científico.

Salienta-se, ainda, que essa "ação revolucionária" não se ateve apenas ao curso de Engenharia Agronômica, mas os cursos de Pedagogia e Letras ocorreram nesse formato de duas turmas de aproximadamente 60 vagas em cada um deles; uma turma ofertada em um Departamento e a outra, embora vinculada a um Departamento, ofertada no interior do território de Assentamento de Reforma Agrária - conforme a terceira coluna do Quadro 2.

Registre-se que o advento do Pronera possibilitou a realização dos cursos de alfabetização de jovens e adultos e cursos de formação de professores na modalidade normal médio e superior. No entanto, esses cursos inscrevem-se na modalidade especial, ou seja, não se configuraram na universidade como oferta contínua, o que deixava entrever que a Educação do Campo não havia sido incorporada à universidade, ou seja, não estava consolidada no sentido de entrar na estrutura permanente dos processos formativos que a universidade desenvolve em seu cotidiano. De modo que, em 2007, no processo de reformulação curricular, organizou-se um movimento interno de professores militantes/pesquisadores e extensionistas em Educação do Campo a fim de incluir um componente curricular intitulado Educação do Campo nos currículos dos cursos de licenciatura com entrada contínua da universidade.

A inclusão desse componente curricular no Curso de Pedagogia tem possibilitado discutir as concepções e os princípios da Educação do Campo no Brasil a partir dos aportes teóricos clássicos e do Movimento Nacional Por Uma 
Educação do Campo, e ainda sustentar o debate da educação do campo da formação inicial dos professores, trazendo as demandas e problemáticas do campo para a formação de professores da educação básica. Enfatiza-se que no interior do estado da Bahia, onde geralmente são ofertados a quase totalidade dos cursos de Pedagogia da UNEB, a maioria dos aspirantes a pedagogos, possivelmente, atuará no campo ou, em algumas situações, atuará em escolas urbanas que receberão estudantes do campo.

Em 2010, dois projetos distintos do Pronera foram realizados: o Programa de Apoio à Formação Superior em Licenciatura em Educação do Campo (Procampo) e ProJovem Campo/ Saberes da Terra. O Procampo é uma política de formação de educadores conquistada também a partir da pressão e das demandas apresentadas ao Estado pelo Movimento da Educação do
Campo. Pautada desde a primeira Conferência Nacional: Por uma Educação Básica do Campo, realizada em 1998, a exigência de uma política pública específica para dar suporte e garantir a formação de educadores do próprio campo vai se consolidar como uma das prioridades requeridas pelo Movimento ao término da II Conferência Nacional Por Uma Educação do Campo, realizada em 2004, cujo lema era "Por um Sistema Público de Educação do Campo".

Embora o Procampo tenha sido destinado a operar no âmbito das universidades federais, a UNEB concorreu ao Edital da União no 2, de 28 de abril de 2008 (BRASIL, 2008), recebendo parecer técnico de aprovação n⿳0 017/2008 para ofertar 60 (sessenta) vagas para o Curso de Licenciatura em Educação do Campo. A turma foi ofertada no Departamento de Educação Campus XIII - município de Itaberaba.

Quadro 3 - Cursos/Projetos UNEB/ProJovem/Procampo

\begin{tabular}{|c|c|c|c|c|}
\hline Cursos/Projetos & $\begin{array}{c}\text { Território de } \\
\text { Identidade/Municipios }\end{array}$ & Ano & Público Inicial & Público Final \\
\hline $\begin{array}{r}\text { Projovem Campo Saberes da } \\
\text { Terra - ProJovem }\end{array}$ & $\begin{array}{r}\text { Territórios de } \\
\text { Identidade: Itaparica, } \\
\text { Velho Chico, Nordeste II } \\
\text { e Sisal }\end{array}$ & 2010 & 798 & 171 \\
\hline $\begin{array}{r}\text { Licenciatura em Educação do } \\
\text { Campo - Procampo }\end{array}$ & Itaberaba & 2010 & 60 & 49 \\
\hline
\end{tabular}

Fonte: Elaborado pelas autoras deste artigo com base em Universidade do Estado da Bahia (2020).

O Programa Nacional de Inclusão de Jovens (ProJovem Campo - Saberes da Terra) constitui-se em um Programa educacional proposto para a juventude camponesa com faixa etária de 18 a 29 anos que por algum motivo fora excluída da escola. Organizado no formato da modalidade de Educação de Jovens e Adultos, o Programa permite aos jovens retomar o seu processo educacional e completar a escolaridade em nível fundamental, integrada à qualificação profissional.

No estado da Bahia, o Programa iniciou-se em 2010 pela Secretaria Estadual de Educação, em parceria com as secretarias munici- pais de educação, com a UNEB; com o Fórum Estadual de Educação do Campo (FEEC); com os Conselhos Estaduais dos Territórios da Cidadania; e com as Diretorias Regionais de Educação (DIREC). A UNEB, por meio da Pró-Reitoria de Extensão (PROEX,) participou dessa oferta realizando ações de formação continuada dos professores e coordenadores que atuaram no Programa. No período de 2010 a 2012, foram 38 coordenadores das turmas, distribuídos em 04 Territórios de Identidade da Bahia: Território de Identidade Itaparica, Território de Identidade Semiárido Nordeste II, Território de Identidade Velho 
Chico e Território de Identidade Sisal. 0 curso ofertou 20 turmas, compostas, cada uma, por 40 cursistas, distribuídas nos citados Territórios de Identidade, sendo desenvolvido em seis módulos, perfazendo uma carga horária total de 360 horas.

Assim, conforme avaliação final, o relatório expõe que foram consideradas:

Potencialidades do Projeto: autoformação da equipe e formadores, produção do material de apoio, proposta da formação, realização das oficinas nos territórios, o processo de avaliação permanente, visitas de acompanhamento, o trabalho com o currículo integrado, a articulação com a pesquisa e a docência no campo.

Fragilidades: fluxo contínuo dos educadores; falta de articulação UNEB/SEC; logística de alguns módulos em alguns territórios; realização do tempo comunidade; operacionalização do Programa nos territórios, intervalos longos entre os módulos, resultante da falta de retorno da SEC, rotatividade dos formadores; formato do curso que não conseguiu apresentar-se como Curso de Especialização, como era proposta da Universidade; não realização da segunda etapa da formação; número de educadores (as) que concluiu a formação com carga horária completa. (UNIVERSIDADE DO ESTADO DA BAHIA, 2012b, p. 49, grifo do autor).

Observa-se, sobremaneira, a importância do aprimoramento de articulações entre as instâncias de gestão do projeto, tanto para a implantação quanto para o desenvolvimento do projeto, de modo que os processos formativos ocorram com fluidez, continuidade e relacionados aos interesses e expectativas dos sujeitos em formação. Trata-se do cuidado e fortalecimento do trabalho coletivo, anteriormente citado.

No âmbito da Pós-Graduação, foram ofertados curso de Especialização Lato Sensu, os quais se encontram organizados no Quadro 4 a seguir.

Quadro 4 - Cursos de Especialização realizados

\begin{tabular}{|c|c|c|c|c|}
\hline CURSO & $\begin{array}{l}\text { DEPARTAMENTO/ } \\
\text { MUNICÍPIO }\end{array}$ & OBJETIVO & PERÍODO & $\begin{array}{l}\text { INGRESSOS/ } \\
\text { CONCLUINTES }\end{array}$ \\
\hline $\begin{array}{l}\text { Especialização } \\
\text { em Educação do } \\
\text { Campo }\end{array}$ & $\begin{array}{l}\text { Departamento de } \\
\text { Educação - Campus } \\
\text { VII - Senhor do } \\
\text { Bonfim } \\
\\
\text { Departamento de } \\
\text { Educação - Campus } \\
\text { XII - Guanambi }\end{array}$ & $\begin{array}{l}\text { Produzir conhecimento sobre Educa- } \\
\text { ção do Campo, qualificando profes- } \\
\text { sores, gestores, coordenadores peda- } \\
\text { gógicos e educadores sociais, a partir } \\
\text { de um percurso pedagógico transdis- } \\
\text { ciplinar que provoque o diálogo per- } \\
\text { manente entre teoria-prática, ensino } \\
\text { e pesquisa. } \\
\text { Mobilizar diferentes profissionais } \\
\text { para dialogarem com as questões da } \\
\text { realidade do campo, ampliando as } \\
\text { possibilidades de maior compreen- } \\
\text { são e intervenção dos sujeitos locais } \\
\text { nos processos em que estão inseri- } \\
\text { dos, fortalecendo seus laços identitá- } \\
\text { rios com o seu Território de origem. }\end{array}$ & $x^{2}$ & $49 / 40$ \\
\hline $\begin{array}{l}\text { Especialização } \\
\text { em Educação de } \\
\text { Jovens e Adultos } \\
\text { (EJA) }\end{array}$ & $\begin{array}{l}\text { Departamento de } \\
\text { Educação - Campus } \\
\text { X - Teixeira de } \\
\text { Freitas }\end{array}$ & $\begin{array}{l}\text { Refletir ações de intervenções nas } \\
\text { políticas públicas e práticas de Edu- } \\
\text { cação de Jovens e Adultos numa pers- } \\
\text { pectiva emancipatória. }\end{array}$ & $2012-2014$ & $40 / 24$ \\
\hline
\end{tabular}

Fonte: Elaborado pelas autoras deste artigo com base em Universidade do Estado da Bahia $(2014,2018)$. 
Os projetos de Especialização Lato Sensu nas áreas de Educação do Campo e EJA visaram, principalmente, o aprofundamento teóricometodológico para o exercício docente. Nessa proposição, a universidade atende à demanda de interesse de uma categoria específica, ao mesmo tempo em que cumpre a missão de promover projetos de natureza não só da formação inicial, mas também de formação continuada.

Segundo consta no setor de Assessoria de Comunicação (ASCOM) da UNEB, em agosto de 2015 a UNEB realiza o Seminário de Educação do Campo: Memória, Avaliação e Perspectivas (UNIVERSIDADE DO ESTADO DA BAHIA, 2015). Este Seminário expressou um conjunto de esforços da Universidade, juntamente com docentes, pesquisadores, extensionistas e representantes de Movimentos Sociais e Sindicais Populares do Campo, para dar visibilidade aos estudos e produções sobre Educação do Campo e Agroecologia, no âmbito dos Departamentos da UNEB, bem como para avaliar as ações já realizadas e em andamento, a fim de contribuir para a proposição e efetivação de políticas públicas de Educação para os povos que vivem e trabalham no campo, articuladas com um projeto de desenvolvimento territorial integrado e sustentável, que considerasse as múltiplas dimensões da existência humana.

Destaca-se que o folder de divulgação do evento (UNIVERSIDADE DO ESTADO DA BAHIA, 2020) torna pública a temática que enreda o conteúdo e a metodologia de trabalho, qual seja, "Memória, Avaliação e Perspectivas"; evidencia a participação efetivas de pelo menos dez representações de Movimentos/Organizações, a saber: MST, MLT, CETA, FETAG, FATRES, FETRAF, Fundo de Pasto, Fórum Estadual de Educação do Campo, Rede das Escolas Famílias Agrícolas (Refaisa), Centro de Agroecologia do Semiárido e Movimento dos Pequenos Agricultores. Segundo informações das listas de frequência do evento, participaram 74 pessoas. Os Departamentos da UNEB, representados por docentes, pesquisadores/as e extensionistas foram dos campi de Irecê, Juazeiro, Bom Jesus da Lapa, Guanambi, Alagoinhas, Teixeira de Freitas, Senhor do Bonfim, Barreiras, Conceição do Coité e Salvador.

Observa-se no folder de divulgação (UNIVERSIDADE DO ESTADO DA BAHIA, 2020), sobretudo, o trabalho coletivo entre universidade e os Movimentos, o qual ocorre desde o planejamento/organização do evento, definição de objetivos, articulação para a participação dos sujeitos, a realização da Mística para cada mesa de discussão/atividade do referido seminário até a sua finalização com a produção da Carta- Documento.

A Mística é uma atividade sociopolítica e cultural produzida na organicidade dos Movimentos Sociais e Sindicais Populares do Campo que instiga e, ao mesmo tempo, é instigada pela intencionalidade que guia o fazer, o pensar e o sentir do coletivo que se encontra em atividade. Dessa prerrogativa, é forçoso afirmar que a UNEB, na realização de atividades relacionadas à Educação do Campo, Agroecologia e Desenvolvimento Territorial, coloca a mística como elemento de formação, produzido pelos Movimentos, entrelaçando-se com a formação e as pessoas presentes nesse processo.

Nesse sentido, o educador-militante-poeta Ademar Bogo (2002, p. 23) assevera que o movimento da Mística, "Nos mais sensíveis, aparece como reflexo daquilo que faz e sente. A cada passo revela pedaços da verdade que se escondem por inteiro nas dobras do desconhecido". Ademais, a Mística "ao mesmo tempo em que brota e se alimenta da causa, faz a causa e a si própria" (BOGO, 2002, p. 53). Sendo assim, pode-se considerar o compromisso social da UNEB com a Educação do Campo também como causa, perseguida ao longo de sua história. $\mathrm{Ou}$ seja, principalmente no campo da pesquisa e extensão, a produção do conhecimento se desenvolveu de modo "desinteressado" ${ }^{4}$ da lógica da produção acadêmica hegemônica, para

4 Termo utilizado por Gramsci (1997) no livro A organização da cultura para demarcar o papel político, organizativo e intencional da educação e da escola contra a lógica do sistema hegemônico de produção em que tanto a educação quanto a escola estão inseridas. 
alinhar-se em favor das lutas sociais, as quais tomam como centralidade a Questão Agrária e a Reforma Agrária Popular.

Todavia, no trabalho formativo da UNEB não se verifica uma iniciativa individualizada, própria, mas diálogos com demandas propositivas, originadas da articulação entre pesquisadores/ as, extensionistas e Movimentos Sociais e Sindicais Populares do Campo. Cabe destacar que o conceito de diálogo, na perspectiva freireana, é possibilidade de superação de relações hierárquicas, rígidas e lineares, ou melhor dizendo, "ao fundar-se no amor, na humildade, na fé nos homens, o diálogo, se faz uma relação horizontal, em que a confiança de um polo no outro é consequência óbvia" (FREIRE, 2004, p. 81).

Desse entendimento e prática, a realização do Seminário de Educação do Campo: Memória, Avaliação e Perspectivas no mês de agosto do ano de 2015 suscitou, de modo significativo, o avanço da organicidade dos trabalhos na área de Educação do Campo, Agroecologia e Desenvolvimento Territorial, pois cumprido o objetivo de trazer à tona do debate as ações realizadas ao longo do percurso histórico da UNEB e avaliações correspondentes, a conclusão do referido seminário se efetivou com o encaminhamento de um documento intitulado "Carta Documento: pela construção e implementação de uma Política de Educação do Campo na UNEB" (UNIVERSIDADE DO ESTADO DA BAHIA, 2020).

O supracitado documento apresenta à Universidade do Estado da Bahia e ao Governo do Estado (Secretarias da Casa Civil, da Educação, do Desenvolvimento Rural, de Relações Institucionais e de Promoção da Igualdade Racial) os resultados dos trabalhos construídos ao longo de vinte e seis anos na história dessa universidade, para que seja assegurada, por estas instituições, a implantação de uma política permanente em Educação do Campo, no âmbito da UNEB. Ademais, o teor do documento apresenta considerações e proposições, ao mesmo tempo em que os participantes do Seminário se comprometem a realizar as ações demandadas à UNEB no que concerne à Educação do Campo e a cumprir os princípios que a caracterizam, assim como reafirmam a necessidade de garantir condições objetivas adequadas para o desenvolvimento dessas demandas.

Chama-se a atenção, nesse período de catarse do próprio percurso histórico percorrido, que mais uma vez se apresentam as duas características discutidas anteriormente: 1) a construção dos processos formativos pelo trabalho coletivo entre Movimentos Sociais e Universidade; e 2) Atendimento das demandas de formação apresentadas pelos Movimentos.

Considera-se que dessas características emanam o significado e a importância da Carta Documento para o fortalecimento e a ampliação das ações e políticas de Educação do Campo na UNEB, o que implicou, necessariamente, na criação do Centro Acadêmico de Educação do Campo e Desenvolvimento Territorial, conforme Portaria do Conselho Universitário (CONSU) no 1.265 , de 11 de abril de 2017 (UNIVERSIDADE DO ESTADO DA BAHIA, 2012, 2017a), que cria e implanta o referido Centro. Por conseguinte, registra-se que o período entre 2003 e 2010 corresponde a uma organicidade mais sistematizada e coordenada pela PROEX. Como já mencionado anteriormente, no âmbito da UNEB esse é o órgão de onde se articula o trabalho coletivo entre a universidade e os movimentos, se originam e se organizam os pares dialéticos da Organização do Trabalho Pedagógico, a saber, objetivo/ avaliação e conteúdo/forma dos projetos de cursos supracitados.

Para tanto, é nesse período que a equipe de coordenação, composta por três docentes e três técnicos-administrativos, busca institucionalizar de forma mais sistemática as ações ali desenvolvidas, organizando-se no que se denominou Núcleo de Educação do Campo (Educampo), e elabora o regimento desse Setor (vinculado à Proex) com a seguinte definição:

O Núcleo de Educação do Campo - EDUCAMPO - através da Pró-Reitoria de Extensão da Universidade do Estado da Bahia - tem por finalidade, 
integrar, sistematizar, orientar e promover ações de pesquisa e extensão universitária acerca da Educação do Campo, assegurando o suporte necessário à elaboração e desenvolvimento de Projetos voltados para os sujeitos sociais do campo. (UNIVERSIDADE DO ESTADO DA BAHIA, 2008, p. 3).

Todavia, infere-se que, particularmente nesse período, três cursos de graduação com 06 (seis) turmas estavam sendo realizados ao mesmo tempo, em Departamentos distintos, conforme apresentado no Quadro 2, e, ainda, o componente curricular Educação do Campo sendo ofertado nos cursos (regulares de Pedagogia, em dez Departamentos distintos). Tratou-se de um cenário em que muitos docentes, pesquisadores e extensionistas se encontravam ocupados com esse intenso processo de formação de educadoras e educadores do campo, em nível superior, mas sem articulação efetiva entre os Departamentos. Daí observa-se que as ações de articulação entre os movimentos e o próprio grupo articulador, no âmbito da universidade, estiveram mais centradas em ações dos próprios Departamentos/cursos do que em escala ampla da abrangência da universidade, como vem ocorrendo desde ano de 2015 até o momento atual. Talvez o contexto e a situação de dedicação exclusiva aos referidos cursos tenham ocasionado a não realização de ações articuladoras mais amplas, no sentido das relações entre os Movimentos e a UNEB. $\mathrm{E}$, ainda, pelas mesmas razões se observa um desaquecimento da organicidade interna para a Educação do Campo.

Entre 2010 e 2014 os trabalhos e a dinâmica da articulação da Educação do Campo são marcados por um período de arrefecimento mais acentuado, em que pese o andamento de cursos como Bacharelado em Direito, Licenciatura em Educação do Campo, Especialização Lato Sensu em Educação do Campo, no DEDC-VII (Senhor do Bonfim). 0 referido desaquecimento se amplia no início do ano de 2014, na gestão do primeiro mandato do atual Reitor, o que resultou no não encaminhamento do Regimento Interno do Educampo (UNIVERSIDADE DO ESTADO DA BAHIA, 2008), anteriormente citado. Aqui se observa a centralidade de contradições que, conforme salienta Ferreira (2015, p. 47),

[...] em larga medida, é a própria contradição que sustenta os passos e compassos mobilizadores de mudanças e transformações que atendam às necessidades dos sujeitos sociais e coletivos. No entanto, é preciso considerar que as situações de contradição devem ser percebidas pelo coletivo dos sujeitos, e não pontualmente por um ou outro indivíduo.

Esse processo histórico de implementação de uma política em prol da luta social dos povos campesinos não se realiza sem a prerrogativa de uma tomada de consciência coletiva pela prática social de indagar e analisar as situações concretas da realidade em que estamos inseridos. De modo contundente, a ação individual dificulta ainda mais os processos de transformação, haja vista que, isoladamente, o resultado é ínfimo, desprovido de engajamento, de participação e da possibilidade de construção coletiva da realidade social de que os sujeitos coletivos necessitam (FERREIRA, 2015). Daí que, pelo posicionamento crítico e trabalho coletivo entre os sujeitos que compõem grupo articulador, é possível lidar com a contradição em favor do fortalecimento da própria coletividade e dos objetivos pretendidos com os processos formativos que interessam implementar.

Nesse sentido, a realização do Seminário de Educação do Campo: Memória, Avaliação e Perspectivas (UNIVERSIDADE DO ESTADO DA BAHIA, 2015) se configurou como espaço de reflexão crítica, mobilizador de mudanças e transformações possíveis naquele momento histórico, de onde se explicitou a demanda de criação e implementação do CAECDT. Na estrutura regimental da UNEB, o Centro se constitui como órgão suplementar interdisciplinar, atualmente vinculado à Reitoria. Possui sede própria em Conceição do Coité e sua estrutura física foi doada oficialmente pela Lei Municipal n 777, de 10 de junho de 2016 (CONCEIÇÃO DO COITÉ, 2016). 
Trata-se também de um espaço de referência para a produção de conhecimentos acerca dos fenômenos educativos nas áreas de Educação do Campo, Agroecologia e Desenvolvimento Territorial Sustentável, concernentes às demandas dos/as trabalhadores/as camponeses/as vinculados/as ao Movimento Nacional e Regional da Educação do Campo. Essa produção ocorre pelo trabalho de ensino de pós-graduação (lato e stricto sensu), pesquisa e extensão, com vistas à formação de Educadores, Formação Profissional e Tecnológica em nível de graduação e Pós-Graduação.

Assim, o Centro tem como objetivo coordenar, integrar, sistematizar, orientar e promover ações de ensino, pesquisa e extensão, numa perspectiva interdisciplinar, assegurando o suporte necessário à elaboração e desenvolvimento de ações voltadas para e com os sujeitos sociais do campo, com vistas ao desenvolvimento territorial sustentável e solidário. Constata-se no seu Projeto de Criação e Implantação a intencionalidade do Grupo de Articulação da Educação do Campo, Portaria no 1.002, de 15 de abril de 2016 (UNIVERSIDADE DO ESTADO DA BAHIA, 2016a), e do Grupo de Pesquisa intitulado Educação do Campo: Trabalho Contra-hegemonia e Emancipação Humana (GEPEC/UNEB/CAECDT) aglutinarem o trabalho de docentes, pesquisadores e extensionistas, visando ao desenvolvimento de um trabalho científico e formativo de perspectiva crítica e emancipadora, voltado para o atendimento das demandas dos sujeitos coletivos do campo. A seguir no Quadro 5, encontram-se os projetos e as ações do CAECDT/UNEB no período de 2016 aos dias atuais (nov. 2020).

Quadro 5 - Projetos e Ações do CAECDT / UNEB 2016-2020

\begin{tabular}{|c|c|c|}
\hline PROJETO & OBJETIVO & STATUS \\
\hline $\begin{array}{l}\text { Jornada Universitária } \\
\text { em Defesa da Reforma } \\
\text { Agrária Popular } \\
\text { (JURA) }\end{array}$ & $\begin{array}{l}\text { Debater sobre o Direito Agrário, questão agrária e as } \\
\text { condições de produção da vida no campo. } \\
\text { Público: Pesquisadores, extensionistas, estudantes de } \\
\text { graduação e pós-graduação, movimentos sociais e sin- } \\
\text { dicais populares do campo. }\end{array}$ & $\begin{array}{l}\text { Em andamento desde abril } \\
\text { de 2016, ocorre anual- } \\
\text { mente. }\end{array}$ \\
\hline $\begin{array}{l}\text { Encontro Baiano de } \\
\text { Educação do Campo } \\
\text { (EBEC) }\end{array}$ & $\begin{array}{l}\text { Tem como objetivo reunir os sujeitos sociais envolvi- } \\
\text { dos com a discussão da Educação do Campo, com vis- } \\
\text { tas ao aprofundamento da conjuntura atual, à sociali- } \\
\text { zação das produções acadêmico-científicas, relatos de } \\
\text { experiências em espaços escolares e não escolares, no } \\
\text { campo do ensino, da pesquisa e da extensão. Disponí- } \\
\text { vel em: } \\
\text { https://encontroeducampo.wixsite.com/uneb }\end{array}$ & $\begin{array}{l}\text { Em andamento desde agos- } \\
\text { to de } 2016 \text {, é um evento de } \\
\text { extensão universitária que } \\
\text { ocorre a cada dois anos. } \\
\text { Especialmente em } 2020 \\
\text { foi adiado em função da } \\
\text { situação de pandemia da } \\
\text { Covid - } 19 \text {. }\end{array}$ \\
\hline $\begin{array}{l}\text { Seminário de } \\
\text { Intercâmbio } \\
\text { Formativo entre } \\
\text { Estudantes de } \\
\text { Graduação, Pós- } \\
\text { Graduação e Educação } \\
\text { Básica }\end{array}$ & $\begin{array}{l}\text { Trata-se de uma atividade de cunho acadêmico-cientí- } \\
\text { fica- cultural com o objetivo de promover a socializa- } \\
\text { ção dos estudos e experiências formativas dos cursos } \\
\text { realizados em nível da Educação Básica, Graduação e } \\
\text { Pós-Graduação - Mestrado Profissional em Educação } \\
\text { e Diversidade, com vistas ao fortalecimento, contri- } \\
\text { buições e proposições para processos formativos dos } \\
\text { cursos envolvidos. }\end{array}$ & $\begin{array}{l}\text { Em andamento desde } \\
\text { novembro de } 2019 \text {, ocorre } \\
\text { anualmente. }\end{array}$ \\
\hline $\begin{array}{l}\text { Projeto Conexões } \\
\text { Camponesas: } \\
\text { Fortalecendo a } \\
\text { Educação do Campo }\end{array}$ & $\begin{array}{l}\text { Os sujeitos participantes são Professoras, Professores, } \\
\text { Gestores, Coordenadoras, Coordenadores, Movimen- } \\
\text { tos Sociais, Estudantes de Graduação e de Pós-Gra- } \\
\text { duação. Contamos com um quantitativo de aproxi- } \\
\text { madamente } 1.800 \text { pessoas inscritas, representando a } \\
\text { participação de } 90 \text { municípios baianos no projeto. Os } \\
\text { resultados esperados apontam para a ampliação de } \\
\text { conhecimentos acerca das concepções e princípios da } \\
\text { Educação do Campo e Educação de Jovens e Adultos } \\
\text { que subsidiarão estudos e proposições para o ensino. }\end{array}$ & $\begin{array}{l}\text { Em andamento desde julho } \\
\text { de } 2020 \text {, com carga horária } \\
\text { de } 170 \text { h, por mediação tec- } \\
\text { nológica e programação no } \\
\text { canal Youtube TV UNEB/ } \\
\text { CAECDT, é um curso que } \\
\text { ocorre semanalmente, pre- } \\
\text { visto até setembro de } 2021 .\end{array}$ \\
\hline
\end{tabular}




\begin{tabular}{|c|c|c|}
\hline $\begin{array}{l}\text { Curso de formação } \\
\text { continuada de } \\
\text { educadores do campo }\end{array}$ & $\begin{array}{l}\text { Propiciar aos educadores um referencial teórico inicial } \\
\text { sobre Educação do Campo em suas diferentes dimen- } \\
\text { sões, bom como debater os desafios para implemen- } \\
\text { tação das Diretrizes Operacionais para a Educação } \\
\text { Básica nas Escolas do Campo no tocante a: currículo, } \\
\text { organização do trabalho pedagógico, gestão. } \\
\text { Publico alvo: } 80 \text { educadores do campo que atuam no } \\
\text { assentamento Terra Vista, educadores das escolas do } \\
\text { campo do município de Arataca-Ba. }\end{array}$ & $\begin{array}{l}\text { Em andamento, desde } \\
\text { julho do } 2015 \text {. }\end{array}$ \\
\hline Feira Agroecológica & $\begin{array}{l}\text { Comercialização de Produtos agroecológicos, livre de } \\
\text { defensivos, além de formação para sustentabilidade e } \\
\text { qualidade de vida. }\end{array}$ & $\begin{array}{l}\text { Em andamento (todas as } \\
\text { quintas feiras no Campus I) } \\
\text { No Campus X ocorre uma } \\
\text { vez por mês. }\end{array}$ \\
\hline $\begin{array}{l}\text { Oficinas de Formação } \\
\text { e Acompanhamento } \\
\text { dos produtores da } \\
\text { Feira Agroecológica }\end{array}$ & $\begin{array}{l}\text { Formação, acompanhamento e avaliação da produção } \\
\text { dos agricultores que comercializam seus produtos na } \\
\text { Feira Agroecológica. } \\
\text { Público: Produtores de assentamentos da Reforma } \\
\text { Agrária e do presídio Lafayte Coutinho que comerciali- } \\
\text { zam seus produtos na Feira Agroecológica. }\end{array}$ & Em andamento \\
\hline $\begin{array}{l}\text { Curso de Formação de } \\
\text { Agentes Populares em } \\
\text { Agroecologia }\end{array}$ & $\begin{array}{l}\text { Oportunizar a troca de conhecimentos, enfatizar os } \\
\text { princípios da agroecologia, dando alternativas para os } \\
\text { agricultores iniciarem seu processo de transição ou } \\
\text { melhorarem suas ações de base agroecológica. } \\
\text { Público: Feirantes e assentados. }\end{array}$ & Em andamento \\
\hline $\begin{array}{l}\text { Retomada da Feira } \\
\text { Agroecológica } \\
\text { da UNEB (Edital } \\
\text { 030/2020 da PROEX) }\end{array}$ & $\begin{array}{l}\text { Comercialização de Produtos agroecológicos, livre de } \\
\text { defensivos, além de formação para sustentabilidade e } \\
\text { qualidade de vida. }\end{array}$ & $\begin{array}{l}\text { Em andamento. Ocorre } \\
\text { semanalmente no Campus I } \\
\text { e Pavilhão do PAF da UFBA } \\
\text { em Ondina - Formato Drive } \\
\text { Thru. }\end{array}$ \\
\hline $\begin{array}{l}\text { Projeto Vi } \\
\text { Mudas da }\end{array}$ & $\begin{array}{l}\text { Produção de mudas da Caatinga para } \\
\text { recaatingamento do Centro e doação. }\end{array}$ & $\begin{array}{l}\text { Em andamento no CAECDT } \\
\text { em Conceição do Coité. }\end{array}$ \\
\hline $\begin{array}{l}\text { Projeto de Metrado } \\
\text { Profissional em } \\
\text { Educação do Campo }\end{array}$ & $\begin{array}{l}\text { Fomentar a produção de conhecimento acerca dos } \\
\text { processos formativos dos educadores que atuam no } \\
\text { campo, como também problematiza a organização do } \\
\text { trabalho pedagógico na escola, sua gestão, formação } \\
\text { continuada, trabalho e implementação de projetos } \\
\text { inovadores teoricamente consistentes e socialmente } \\
\text { relevantes. } \\
\text { Público: destina-se à formação continuada de gradua- } \\
\text { dos em Licenciaturas e em Bacharelados em outras } \\
\text { áreas de conhecimento. }\end{array}$ & Em processo de elaboração \\
\hline $\begin{array}{l}\text { Projeto de } \\
\text { Especialização em } \\
\text { Educação do Campo e } \\
\text { Agroecologia }\end{array}$ & $\begin{array}{l}\text { Realizar Curso de Especialização (Lato Sensu) em Edu- } \\
\text { cação do Campo e Agroecologia com vistas à formaçãao } \\
\text { de profissionais da educação que atuam em espaços } \\
\text { escolares e não escolares, na perspectiva do desen- } \\
\text { volvimento territorial rural sustentável, solidário e da } \\
\text { emancipação humana. } \\
\text { Público: } 50 \text { estudantes, sujeitos do campo. }\end{array}$ & Em processo de tramitação \\
\hline $\begin{array}{l}\text { Curso de Bacharelado } \\
\text { em Agroecologia }\end{array}$ & $\begin{array}{l}\text { Formar, sob a perspectiva da Pedagogia da alternância, } \\
\text { bacharéis em Agroecologia para atender uma popula- } \\
\text { ção jovem e adulta de trabalhadores das áreas rurais e } \\
\text { constitui-se em uma ação com um largo significado na } \\
\text { promoção da justiça social no campo através da demo- } \\
\text { cratização do acesso à educação superior. } \\
\text { Público: } 50 \text { estudantes, sujeitos do campo (total de } \\
100 \text { ) }\end{array}$ & $\begin{array}{l}\text { Realizado processo sele- } \\
\text { tivo (vestibular) ofertado } \\
\text { em parceria com os Depar- } \\
\text { tamentos de Conceição do } \\
\text { Coité e Irecê, fundamen- } \\
\text { tado metodologicamente } \\
\text { pela Pedagogia da Alter- } \\
\text { nância }\end{array}$ \\
\hline
\end{tabular}

Fonte: Elaborado pelas autoras deste artigo com base em dados do CAECDT. 
Alguns dos atuais projetos que o CAECDT realiza compreendem o período de 2015 aos dias atuais. Esse dado, de início, impõe registrar que o elo entre o Seminário de Educação do Campo: Memória, Avaliação e Perspectivas (UNIVERSIDADE DO ESTADO DA BAHIA, 2015) e a criação e implantação do Centro Acadêmico de Educação do Campo e Desenvolvimento Territorial (UNIVERSIDADE DO ESTADO DA BAHIA, 2016b) se fez não só pela emissão da Carta Documento, anteriormente tratada, mas também pelo trabalho realizado pelo Grupo de Articulação da Educação do Campo e do Grupo de Pesquisa GEPEC/UNEB/CAECDT, ambos referenciados acima.

Evidencia-se 05 (cinco) projetos de extensão, sendo três de eventos e dois cursos de extensão; 04 (quatro) projetos relacionados à organização da Feira Agroecológica e formação dos feirantes; e 01 (um) projeto de atividade especificamente agrícola, pois o viveiro é uma produção no espaço físico do CAECDT, no município de Conceição do Coité.

Atualmente, no ensino de graduação, segundo o Projeto Político-Pedagógico do curso de Bacharelado em Agroecologia, por questões regimentais, não foi possível a oferta própria do CAECDT, mas a parceria com os Departamentos de Irecê (Campus XVI) e de Conceição do Coité (Campus XIV), situado no mesmo município, favoreceu a elaboração e gestão do curso que, oficialmente, está vinculado ao referido Departamento. Esse dado explicita, ainda, a potencialidade da articulação da Educação do Campo, o lugar de referência que o coletivo ocupa nas instâncias universitárias para o fortalecimento de ações interdepartamentais. Tais ações configuram dialeticamente a sua particularidade pela experiência do trabalho coletivo e interdisciplinar e a sua universalidade na experiência multicampi, pela qual estende as mesmas ações para várias localidades onde a UNEB atua.

No campo da pós-graduação, embora o Grupo de Articulação esteja buscando o reconhecimento do CAECDT como unidade acadêmica para que tenha a condição de ofertar essa modalidade de ensino, ao menos dois desafios estão colocados nessa direção: 1) ampliar as atividades de pesquisas e apresentação de projetos de iniciação científica, pois essa pode ser uma alternativa para ampliar a produção intelectual do Grupo Articulador; 2) reservar carga horária de trabalho no âmbito dos departamentos para o trabalho pedagógico na pós-graduação - ambos os desafios se ancoram no limite de tempo, em razão das várias frentes de trabalho que esse grupo assume.

Ademais, a partir da criação do CAECDT, dois livros foram publicados, como atividade específica do grupo de pesquisa GEPEC/UNEB/ CAECDT: livro I, intitulado Educação do Campo e formação contra-hegemônica: estudos de relações/interações das práticas educativas $e$ demandas educacionais, organizado por Domingos Rodrigues Trindade e Maria Dorath Bento Sodré (2017); e livro II, intitulado Práticas educativas nas Escolas do Campo em outros espaços educativos dos territórios rurais, organizado por Luzeni Ferraz de Oliveira Carvalho e Maria Jucilene Lima Ferreira (2020). Um terceiro livro, abordando a temática Educação do Campo e Agroecologia, encontra-se sob a organização de Rosana Mara Chaves Rodrigues, Maria Dorath Bento Sodré, Francisco Brito e Gilmar dos Santos Andrade, com chamada aberta para submissão de artigos.

E, ainda, se verifica em alguns currículos (Plataforma Lattes) de docentes, nos anais de eventos, na exposição de lives por docentes, pesquisadoras/es e extensionistas da UNEB a existência de linhas e grupos de pesquisas na área de Educação do Campo e Agroecologia, mas dado o limite de abrangência deste artigo, não serão apresentados.

\section{Considerações conclusivas}

Ao longo do percurso histórico de atuação da Universidade do Estado da Bahia se observa, sobretudo, que o trabalho ali realizado buscou desempenhar a função social da universidade de modo articulado às demandas 
dos movimentos sociais populares do campo. A partir dessa intencionalidade, a elaboração, desenvolvimento e avaliação dos projetos de cursos para a escolarização de campesinos na educação básica, para o ensino de graduação e Pós-Graduação, assim como os projetos de eventos e cursos de extensão carregam consigo a peculiaridade do trabalho coletivo entre a universidade e movimentos sociais organizados.

Esse trabalho coletivo se materializa pela participação efetiva dos movimentos em todas as etapas de cada projeto. Assim, o atendimento às demandas sociais que os movimentos apresentam contraria políticas de cunho compensatório, porque se caracteriza tanto pelo processo de formação que é desencadeado, quanto pelo reconhecimento e respeito aos sabres, às demandas políticas e de formação apresentadas. Nessa perspectiva, tanto a universidade quanto os movimentos sociais se favorecem de aprendizados mútuos acerca de processos de produção de conhecimento a serviço da produção da vida no campo e da experiência de processos de formação humana de perspectiva crítico-emancipadora.

Ressalta-se que na medida em que a universidade se cerca de compromissos sociais efetivamente articulados à luta social dos povos do campo, contribui para o avanço da soberania popular, a organicidade dos povos nos territórios rurais e para a elevação da consciência social. Todavia isso não se faz isoladamente ou por iniciativa própria, mas por intencionalidade e articulação, pela concepção de ciência a serviço da vida, por assumir princípios formativos ancorados na perspectiva da emancipação humana, pela materialidade de políticas públicas voltadas ao atendimento das demandas sociais. Daí que o Pronera, o ProJovem Campo e o Procampo são políticas públicas que subsidiaram a elaboração e desenvolvimento de projetos relacionados à formação técnica, escolarização e formação de docentes, de engenheiros agrônomos e de bacharéis/bacharelas em Direito.
No caso da UNEB, não só as políticas públicas foram favoráveis, mas as próprias contradições vivenciadas ao longo do percurso histórico corroboraram o movimento de mudanças e transformações na gestão dos projetos em curso, que expressaram situações de recuos e avanços desses projetos, mas não permitiram a sua extinção sumária.

0 Grupo de Articulação, junto ao coletivo ${ }^{5}$ de trabalho do CAECDT, têm buscado implementar novas frentes de trabalho, sob a escuta comprometida com as demandas dos movimentos e com princípios do trabalho coletivo, portanto, sinalizam-se possibilidades de se reafirmar o compromisso social da UNEB com os povos do campo, das águas, das florestas, de terreiro, e de continuar contribuindo, efetivamente, na implementação de novas relações sociais no campo.

\section{REFERÊNCIAS}

BAHIA. Secretaria de Planejamento do Estado da Bahia (SEPLAN). Territórios de Identidade. Disponível em: http://www.seplan. ba.gov.br/modules/conteudo/conteudo. php? conteudo=17\#: : text $=$ Com $\% 20$ o $\% 20$ objetivo $\% 20$ de $\% 20$ identificar, da $\% 20$ especificidade $\% 20$ de $\% 20$ cada $\% 20$ regi $\%$ C3\%A3o. Acesso em: 27 out. 2020.

BOGO, Ademar. 0 vigor da mística. São Paulo: Associação Nacional de Cooperação Agrícola, 2002. (Coleção Caderno de Cultura, 2).

BOGO, Maria Nalva Rodrigues de Araújo. Reflexões sobre o percurso histórico da Educação do Campo na UNEB: Desafios e perspectivas. In: TRINDADE, Domingos Rodrigues da; SODRÉ, Maria Dorath Bento. Educação do Campo e formação contra -hegemônica: Estudos de relações/intervenções da prática educativas e demandas educacionais. Curitiba, PR: CRV, 2017.

BRASIL. Edital da União no 2, de 28 de abril de 2008. Diário Oficial da União: seção 1, Brasília-DF, 28 abr. 2008. Disponível em: https://www.jusbrasil.

5 Esse coletivo é composto por docentes, técnicos-administrativo e estudantes da UNEB, pesquisadoras/es e extensionistas e representantes do FEEC e de Movimentos Sociais e Sindicais Populares do Campo. 
com.br/diarios/DOU/2008/04/28. Acesso em: 11 nov. 2020.

BRASIL. Presidência da República. Casa Civil. Decreto no 7.352, de 04 de novembro de 2010 . Dispõe sobre a política de educação do campo e o Programa Nacional de Educação na Reforma agrária - PRONERA. Disponível em: http://www. planalto.gov.br/ccivil_03/_ato2007-2010/2010/ decreto $/ \mathrm{d} 7352$.htm \#: : text $=$ Decreto $\% 20$ $\mathrm{n} \% \mathrm{C} 2 \% \mathrm{BA} \% 207352$ \&text=DECRETO $\% 20$ N\%C2\%BA\%207.352\%2C\%20DE\%204,que\%20 lhe $\% 20$ confere $\% 200 \% 20$ art. Acesso em: 11 nov. 2020.

CALDART, Roseli S. Caminhos para a transformação da escola. In: AUED, Bernadete W.; VENDRAMINI, Célia R (org.). Temas e problemas no ensino em escolas do campo. São Paulo: Outras Expressões, 2012. p. 26-58.

CARVALHO, Luzeni Ferraz de Oliveira; FERREIRA, Maria Jucilene Lima (org.). Práticas educativas nas Escolas do Campo e em outros espaços educativos dos territórios rurais. Salvador: JM, 2020. Disponível em: http://www.saberaberto. uneb.br/handle/20.500.11896/1648. Acesso em: 07 nov. 2020.

CASTRO, Jorge Abrahão. Dimensão e mensuração da pobrezana Bahia. Salvador: Instituto de Pesquisa Econômica Aplicada (IPEA), 2011. Disponível em: http://www.ipea.gov.br/portal/images/stories/ PDFs/110701_pobrezabahiaabrahao.pdf. Acesso em: 08 ago. 2011.

COMISSÃO PASTORAL DA TERRA (CPT). Conflitos no Campo - Brasil 2019. Goiânia, 2020. Disponível em: https://www.cptnacional.org. br/publicacoes-2/destaque/5167-conflitos-nocampo-brasil-2019. Acesso em: 30 ago. 2020.

CONCEIÇÃO DO COITÉ. Lei Municipal no 777, de 10 de junho de 2016. Diário Oficial do Municipal: Conceição do Coité, ano VIII, edição 805, caderno 1, p. 1, 15 jun. 2016.

FERREIRA, Maria Jucilene Lima. Docência na escola do campo e formação de educadores: qual o lugar do trabalho coletivo? 2015. $244 \mathrm{f}$. Tese (Doutorado em Educação) - Programa de PósGraduação em Educação, Universidade de Brasília (UnB), Brasília, DF, 2015.

FERREIRA, Maria Jucilene Lima. MOLINA, Mônica Castagna. Formação de educadores do campo e trabalho coletivo: refletindo sobre experiências da UNB e da formação docente em Cuba. Revis- ta Congreso Universidad 2016, Habana, Cuba, v. 5, n. 4, 2016. Disponível em: http://www. congresouniversidad.cu/revista/index.php/ congresouniversidad/index. Acesso em: 30 set. 2020.

FIALHO, Nádia Hage. Universidades estaduais no Brasil: pauta para a construção de um sistema nacional articulado de educação. Revista da FAEEBA - Educação e Contemporaneidade, Salvador, v. 21, n. 38, p. 81-93, jul./dez. 2012. Disponível em: https://www.revistas.uneb.br/index.php/faeeba/ issue/view/478. Acesso em: 30 set. 2020.

FREIRE, Paulo. Pedagogia do oprimido. 38. ed. Rio de Janeiro: Paz e Terra, 2004.

GEOGRAFAR. Grupo de Pesquisa do Instituto de Geologia da Universidade Federal da Bahia. Projeto "A Geografia dos Assentamentos na Área Rural". A Leitura Geográfica da Estrutura Fundiária do Estado da Bahia. Banco de Dados, 2013. Disponível em: http://www.geografar.ufba.br/ estruturafundiaria. Acesso em: 28 ago. 2020.

GRAMSCI, Antônio. Os intelectuais e a organização da cultura. Tradução de Carlos Nelson Coutinho. Rio de Janeiro: Civilização Brasileira, 1997.

INSTITUTO BRASILEIRO DE GEOGRAFIA E estatísticA (IBGE). Censo Agropecuário 2006 - Brasil, grandes regiões e unidades da Federação. Rio de Janeiro, 2009. Disponível em: https://biblioteca.ibge.gov.br/visualizacao/ periodicos/51/agro_2006.pdf. Acesso em: 28 set. 2020.

INSTITUTO BRASILEIRO DE GEOGRAFIA E ESTATÍSTICA (IBGE). Pesquisa Nacional por Amostra de Domicílios (PNAD) - Síntese de indicadores 2009. Rio de Janeiro, 2010. Disponível em: https://biblioteca.ibge.gov.br/visualizacao/ livros/liv45767.pdf. Acesso em: 10 set. 2020.

INSTITUTO NACIONAL DE ESTUDOS E PESQUISA ANÍSIO TEIXEIRA (INEP). Divulgados resultados amostrais do SAEB 2019. INEP Notícias, Brasília, DF, 04 nov. 2019. Disponível em: https://www. gov.br/inep/pt-br/assuntos/noticias/saeb/ divulgados-resultados-amostrais-do-saeb-2019. Acesso em: 27 fev. 2020.

MOLINA, Mônica Castagna. Reflexões sobre o significado do protagonismo dos movimentos sociais na construção de políticas públicas de Educação do Campo. In: MOLINA, M. C. (org.). Educação do Campo e Pesquisa II. Brasília, DF: MDA/ 
MEC, 2010. p. 137-149.

MOLINA, Mônica Castagna; ANTUNES-ROCHA, Maria Isabel. Educação do Campo, história, práticas e desafios no âmbito das políticas de formação de educadores - reflexões sobre o PRONERA e o PROCAMPO. Revista Reflexão e Ação, Santa Cruz do Sul, RS, v. 22, n. 2, p. 220-253, jul./dez. 2014. Disponível em: http.//online.unisc.br/seer/índex. php/reflex/índex. Acesso em: 30 set. 2020.

PISTRAK, Moisey M. Fundamentos da escola e do trabalho. 5. ed. Tradução de Daniel Aarão Reis Filho. São Paulo: Expressão Popular, 2000.

TRINDADE, Domingos Rodrigues da; SODRÉ, Maria Dorath Bento (org.). Educação do Campo e formação contra-hegemônica: estudos de relações / interações das práticas educativas e demandas educacionais. Curitiba: CRV, 2017.

UNIVERSIDADE DO ESTADO DA BAHIA (UNEB). Projeto de Curso Licenciatura Plena em Pedagogia da Terra. Salvador, 2003.

UNIVERSIDADE DO ESTADO DA BAHIA (UNEB). Departamento de Ciências Humanas, Campus IX. Relatório final do curso de Engenharia Agrônoma. Barreiras, BA, 2006.

UNIVERSIDADE DO ESTADO DA BAHIA (UNEB). Regimento Interno do Núcleo de Educação do Campo (Educampo). Salvador, 2008.

UNIVERSIDADE DO ESTADO DA BAHIA (UNEB). Relatório Parcial do Desenvolvimento do Curso de Letras (maio a setembro). Salvador, 2010.

UNIVERSIDADE DO ESTADO DA BAHIA (UNEB). Regimento Geral. Salvador, 2012. Disponível em: https://portal.uneb.br/conselhos/wp-content/ uploads/sites/103/2019/02/Regimento-Geral-daUNEB-1.pdf. Acesso em: 11 nov. 2020.

UNIVERSIDADE DO ESTADO DA BAHIA (UNEB). Projeto de Curso de Bacharelado em Direito. Salvador, 2012a.

UNIVERSIDADE DO ESTADO DA BAHIA. Relatório Final do Projeto Saberes da Terra. Salvador, 2012b.
UNIVERSIDADE DO ESTADO DA BAHIA (UNEB). Departamento de Educação, Campus X. Relatório final do curso de especialização em Educação de Jovens e Adultos (EJA). Teixeira de Freitas, BA, 2014.

UNIVERSIDADE DO ESTADO DA BAHIA (UNEB). Seminário de Educação do Campo: memória, avaliação e perspectiva. Salvador, 2015. Disponível em: https://www.youtube.com/ watch?v=jmqqIOW3v70. Acesso em: 15 nov. 2020.

UNIVERSIDADE DO ESTADO DA BAHIA (UNEB). Portaria no 1.002, de 15 de abril de 2016. Salvador, $2016 a$.

UNIVERSIDADE DO ESTADO DA BAHIA (UNEB). Projeto de Criação e Implantação do Centro Acadêmico de Educação do Campo e Desenvolvimento Territorial (CAECDT). Salvador, 2016b. Disponível em: https://www.uneb.br. Acesso em: 30 set. 2020.

UNIVERSIDADE DO ESTADO DA BAHIA (UNEB). Resolução do Conselho Universitário (CONSU). Salvador, 2017a. Disponível em: https://portal. uneb.br/conselhos/wp-ontent/uploads / sites/103/2020/03/RESOLU\%C3\%87\%C3\%830N\%C2\%BA-1265_2017.pdf. Acesso em: 27 fev. 2020.

UNIVERSIDADE DO ESTADO DA BAHIA (UNEB). Plano de Desenvolvimento Institucional. Salvador, 2017b. Disponível em: www.uneb.br. Acesso em: 11 nov. 2020.

UNIVERSIDADE DO ESTADO DA BAHIA (UNEB). Departamento de Educação, Campus VII. Relatório final do curso de especialização em Educação do Campo. Senhor do Bomfim, BA, 2018.

UNIVERSIDADE DO ESTADO DA BAHIA (UNEB). Centro Acadêmico de Educação do Campo e Desenvolvimento Territorial (CAECDT). Relatório anual. Salvador, 2020. Mimeografado.

Recebido em: 13/11/2020 Aprovado em: 26/01/2021

(cc) EY-NC Este é um artigo publicado em acesso aberto sob uma licença Creative Commons. 